Universidade Tecnológica Federal do Paraná - UTFPR

Campus Ponta Grossa - Paraná - Brasil

ISSN: $1981-3686 /$ v. 05, n. 02: p. 524-530, 2011

D.O.I.: $10.3895 / \mathrm{S} 1981-36862011000200004$
Revista Brasileira deTecnologia

Agroindustrial

\title{
CONTAMINANTES MICROBIOLÓGICOS EM POLPAS DE AÇAí COMERCIALIZADAS NA CIDADE DE BELÉM-PA
}

\section{MICROBIOLOGICAL CONTAMINANTS IN AÇAI PULP TRADED IN BELÉM-PA}

\author{
Kelly de Oliveira Cohen ${ }^{1}$, Virgínia Martins da $\mathrm{Matta}^{2}$, Angela Aparecida Lemos Furtado ${ }^{2}$, Nilce Limeira \\ Medeiros $^{3}$, Renan Campos Chisté ${ }^{4}$ \\ ${ }^{1}$ Embrapa Sede - Brasília - Brasil - kelly.cohen@embrapa.br \\ ${ }^{2}$ Embrapa Agroindústria de Alimentos - Rio de Janeiro - Brasil - vmatta@ctaa.embrapa.br; \\ afurtado@ctaa.embrapa.br \\ ${ }^{3}$ Laboratório Nacional Agropecuário - LANAGRO - Belém - Brasil - nilce.limeira@gmail.com \\ ${ }^{4}$ Universidade Estadual de Campinas - UNICAMP - Campinas - Brasil - renanchiste@gmail.com
}

\begin{abstract}
Resumo
O açaizeiro (Euterpe oleracea Mart.), palmeira nativa da Amazônia, se destaca, entre os diversos recursos vegetais, por sua polpa, rica em antocianinas, que é largamente consumida nos estados produtores e cuja exportação para outros estados do Brasil e para o exterior vem crescendo continuamente. As condições atuais de processamento do açaí, realizado em pequenos estabelecimentos espalhados em diversos pontos de comercialização, podem representar um risco potencial à saúde dos consumidores em função das deficiências higiênico-sanitárias dos mesmos. Este trabalho teve como objetivo analisar a qualidade sanitária da polpa de açaí em dez pontos de comercialização da cidade de Belém, PA, entre eles quatro supermercados, duas feiras livres e quatro pontos de venda ("batedeiras"). Foram realizadas análises de: Salmonella, coliformes fecais, Escherichia coli e fungos filamentosos e leveduras. Das dez amostras analisadas, todas apresentaram coliformes fecais no valor de $\geq 1,10 \times 102 \mathrm{NMP} / \mathrm{g}$ e fungos filamentosos e leveduras variando de 9,0x102 a 5,5x105 UFC/g. Em duas amostras foi verificada a presença de Salmonella e nove apresentaram Escherichia coli. De acordo com os resultados, verificou-se que todas as amostras encontraram-se fora dos padrões recomendados pela ANVISA, indicando a necessidade de implantação de Boas Práticas de Fabricação neste importante segmento da região.
\end{abstract}

Palavras-chave: Euterpe oleracea, higienização, Salmonella, Escherichia coli, fungos, leveduras.

\section{Introdução}

O açaí (Euterpe oleracea Mart) é uma palmeira abundante no estuário do rio Amazonas, em terrenos de várzeas, igapós e terra firme, encontrando-se no Estado do Pará as suas maiores reservas naturais (CAVALCANTI, 1991; NOGUEIRA et al., 1995).

Dos frutos do açaizeiro é extraída uma polpa de coloração vinho, bastante apreciada pela população da região amazônica, que costuma consumi-la com farinha de mandioca ou tapioca, com 
ou sem açúcar, acompanhada de peixe frito, camarão ou carne de sol.

A legislação brasileira define polpa de fruta como o produto não fermentado, não concentrado, não diluído, obtida pelo esmagamento de frutos polposos, através de um processo tecnológico adequado, com um teor mínimo de sólidos totais provenientes da parte comestível do fruto, específico para cada um destes. No caso específico do açaí, polpa de açaí ou simplesmente açaí são produtos extraídos da parte comestível do fruto do açaizeiro (Euterpe oleracea Mart.) após amolecimento, através de processos tecnológicos adequados (BRASIL, 2000).

Os produtos obtidos do fruto do açaí são classificados (BRASIL, 2000) de acordo com a adição ou não de água e o teor de sólidos totais em: polpa de açaí (polpa extraída sem adição de água e sem filtração); açaí grosso ou especial (polpa extraída com adição de água e filtração, apresentando sólidos totais acima de 14\%); açaí médio ou regular (polpa extraída com adição de água e filtração, apresentando sólidos totais entre 11 e 14\%) e açaí fino ou popular (polpa extraída com adição de água e filtração, apresentando sólidos totais entre 8 e 11\%).

Nas regiões produtoras de frutos de açaí, a polpa é extraída no próprio local onde a mesma é comercializada, incluindo pontos específicos de venda (conhecidos popularmente como "batedeiras"), supermercados e feiras-livres. Para o despolpamento são utilizadas as tradicionais despolpadeiras verticais de açaí, também chamadas de "batedores", construídas em aço inoxidável e que operam em batelada.

O açaí geralmente é comercializado, tanto no mercado interno como externo, na forma de polpa congelada. No geral, as polpas de frutas tropicais são comercializadas congeladas, consumidas principalmente para uso doméstico, lanchonetes e restaurantes.

A qualidade das popas de frutas está relacionada com a qualidade da matéria-prima, as condições de transporte e processamento e o tipo de embalagem. No caso do açaí, são inúmeros os problemas enfrentados e, para se estabelecer no mercado, a empresa deve colocar como fator principal de seu produto, a qualidade.

O problema da contaminação dos frutos de açaí inicia-se em sua colheita. Segundo Vasconcelos e Alves (2005), a colheita do açaí é uma operação onerosa e difícil, pois os estipes atingem facilmente de 10 a 15 metros de altura, com o perigo de quebra ou tombamento dos mesmos. O colhedor escala o estipe com auxílio de uma peconha e corta o cacho, na sua base. Após o corte, o cacho é, normalmente, depositado no solo. Esta prática faz com que os frutos entrem em contato com o solo, deixando-os suscetíveis à contaminação, sendo de fundamental importância o uso de algum anteparo que evite esse contato.

Após a colheita, realiza-se a debulha, que consiste da remoção dos frutos dos cachos, sendo esta realizada manualmente no próprio local da colheita. Os frutos são depositados, geralmente, em paneiros, que são feitos de palha, material não recomendado para o armazenamento 
de frutos. Durante a colocação dos frutos nos paneiros, estes ficam em contato direto com o chão. Sendo assim, esta é mais uma operação que pode provocar a contaminação dos frutos do açaí.

Outro fator que pode contribuir para a contaminação dos frutos é o transporte, onde, na maioria das vezes, é utilizado o meio fluvial. Muitas vezes os frutos do açaí são transportados em barcos que transportam pescados. Caso os frutos não estejam devidamente acondicionados, pode ocorrer uma contaminação cruzada.

De acordo com Vasconcelos e Alves (2005), o horário matutino é o ideal para o transporte, pois os frutos de açaí estão com a temperatura mais baixa, o que reduz o processo de degradação. Quando o tempo entre a colheita e o despolpamento for superior a 48 horas, os frutos do açaizeiro devem ser transportados em sacos de poliproprileno, com capacidade para até $60 \mathrm{~kg}$, recobertos com gelo. No entanto, deve ser evitado o contato direto dos frutos com o gelo, que pode provocar queimaduras no epicarpo, diminuindo a qualidade do produto e aumentando a área de exposição à contaminação por microrganismos.

Com todos os problemas relacionados ao açaí, desde sua colheita até o transporte dos frutos, os mesmos chegam aos locais de processamento com alta carga microbiana. Esses locais, muitas vezes, não apresentam condições de atender aos padrões de qualidade exigidos pela legislação, o que contribui para a contaminação da polpa, principalmente devido à falta de aplicação das boas práticas de fabricação e à não pasteurização das polpas.

Considerando a escassez de informação na literatura sobre os contaminantes microbiológicos da polpa de açaí, o objetivo deste trabalho foi avaliar a qualidade microbiológica de polpas de açaí comercializadas em alguns pontos de venda da cidade de Belém, PA.

\section{Material e Métodos}

\section{Amostras}

Foram selecionados dez pontos de comercialização de polpa de açaí da cidade de Belém, PA: quatro supermercados, duas feiras livres e quatro "batedeiras". Os pontos foram selecionados em função da localização dos mesmos, a fim de que representassem uma amostra de importantes pontos de consumo do açaí. As amostras $(1 \mathrm{~L})$ foram coletadas em sacos estéreis, sem contato manual, sendo imediatamente congeladas até o momento de realização das análises. 


\section{Análises microbiológicas}

Foram realizadas análises de coliformes fecais (coliformes a $45^{\circ} \mathrm{C}$ ), Escherichia coli, Salmonella, fungos filamentosos e leveduras, de acordo com as metodologias descritas por Vanderzant e Splittstoesser (1992). Os resultados para colifornes fecais foram expressos em Número Mais Provável por grama de amostra (NMP/g) e para fungos filamentosos e leveduras foram expressos em Unidade Formadora de Colônia por grama de amostra (UFC/g).

Embora a legislação atual não exija a análise de fungos filamentosos e leveduras, estas contagens, assim como a E. coli, foram realizadas visando uma melhor avaliação dos contaminantes microbiológicos presentes no açaí.

\section{Resultados e Discussão}

A avaliação das amostras coletadas está resumida na Tabela 1. Foi observado que todas as polpas analisadas estavam fora dos padrões de qualidade sanitária exigidos pela legislação brasileira, que estabelece ausência de Salmonella em 25 g e NMP de coliformes a $45{ }^{\circ} \mathrm{C}$ menor que 3 (BRASIL, 2001). Das dez amostras de polpa de açaí analisadas, todas apresentaram coliformes a $45^{\circ} \mathrm{C}$, no valor de $\geq 1,1 \times 10^{2} \mathrm{NMP} / \mathrm{g}$, em nove foi detectada a presença de Escherichia coli e em duas delas, foi detectada a presença de Salmonella. Em todas as amostras foi observada a presença de fungos filamentosos e leveduras, variando de $9,0 \times 10^{2} \mathrm{UFC} / \mathrm{g}$ a $5,5 \times 10^{5} \mathrm{UFC} / \mathrm{g}$.

Tabela 1 - Análises microbiológicas de amostras de polpa de açaí produzidas e comercializadas na cidade de Belém, PA

\begin{tabular}{|c|c|c|c|c|}
\hline Amostras & $\begin{array}{c}\text { Coliformes a } 45^{\circ} \mathrm{C} \\
(\mathrm{NMP} / \mathrm{g})\end{array}$ & Escherichia coli & $\begin{array}{c}\text { Fungos filamentosos e } \\
\text { Leveduras } \\
\text { (UFC/g) }\end{array}$ & $\begin{array}{c}\text { Salmonella sp (em } \\
25 g)\end{array}$ \\
\hline $\mathbf{A}$ & $\geq 1,1 \times 10^{2}$ & presença & $3,8 \times 10^{4}$ & presença \\
\hline $\mathbf{B}$ & $\geq 1,1 \times 10^{2}$ & presença & $2,2 \times 10^{4}$ & ausência \\
\hline $\mathbf{C}$ & $\geq 1,1 \times 10^{2}$ & presença & $1,3 \times 10^{4}$ & ausência \\
\hline D & $\geq 1,1 \times 10^{2}$ & ausência & $5,5 \times 10^{5}$ & ausência \\
\hline $\mathbf{E}$ & $\geq 1,1 \times 10^{2}$ & presença & $1,1 \times 10^{4}$ & presença \\
\hline $\mathbf{F}$ & $\geq 1,1 \times 10^{2}$ & presença & $2,2 \times 10^{4}$ & ausência \\
\hline $\mathbf{G}$ & $\geq 1,1 \times 10^{2}$ & presença & $4,4 \times 10^{4}$ & presença \\
\hline $\mathbf{H}$ & $\geq 1,1 \times 10^{2}$ & presença & $9,0 \times 10^{2}$ & ausência \\
\hline $\mathbf{I}$ & $\geq 1,1 \times 10^{2}$ & presença & $1,2 \times 10^{4}$ & ausência \\
\hline $\mathbf{J}$ & $\geq 1,1 \times 10^{2}$ & presença & $1,0 \times 10^{4}$ & presença \\
\hline
\end{tabular}

NMP = número mais provável. UFC = unidade formadora de colônia. 
Levantamentos epidemiológicos realizados em vários países situam as Salmonellas entre os agentes patogênicos mais freqüentemente encontrados em surtos de toxinfecção de origem alimentar, tanto em países desenvolvidos, como em países em desenvolvimento (ÁVILA e GALLO, 1996). As Salmonellas são amplamente distribuídas na natureza, sendo o trato intestinal do homem e de animais o seu principal reservatório natural. Os animais domésticos (cães, gatos, pássaros, etc.) podem ser portadores de Salmonellas, representando grande risco, principalmente para crianças (FRANCO e LANDGRAF, 1996).

A presença de coliformes é considerada como indicador de condições de higiene insatisfatórias na produção e/ou manipulação do alimento. O número elevado de coliformes pode não significar contaminação direta com material fecal, mas sim manipulação inadequada, como higiene do manipulador, transporte e acondicionamento inadequados (FRANCO e LANDGRAF, 1996). No caso do açaí, há a necessidade de se implantar as boas práticas agrícolas para minimizar a contaminação dos frutos e as boas práticas de fabricação para a obtenção de produto (polpa), que atenda aos requisitos de qualidade e garanta a segurança do consumidor.

Sousa et al. (2006), objetivando a erradicação da microbiota no suco de açaí testou processos de pasteurização e de fervura em diferentes temperaturas e tempos e avaliou a vida de prateleira. Os sucos foram armazenados sob congelamento a $-18{ }^{\circ} \mathrm{C}$ por 120 dias e avaliados mensalmente quanto às características microbiológicas e físico-químicas. Os resultados microbiológicos do produto in natura demonstraram elevada contaminação por coliformes totais $(>100 \mathrm{NMP} / \mathrm{ml})$ e fecais $(>110 \mathrm{NMP} / \mathrm{ml})$, bolores e leveduras (>300 UFC/mL). A pasteurização a $90{ }^{\circ} \mathrm{C}$ por cinco minutos e fervura por um minuto demonstraram eficiência na erradicação dos microrganismos, manutenção das características sensoriais e conservação do suco de açaí por 120 dias a $-18^{\circ} \mathrm{C}$.

Embora o manipulador utilize avental plástico, touca, máscara e luva nos estabelecimentos onde são realizados o despolpamento e comercialização do açaí, foi verificado que as boas práticas de fabricação não são seguidas. As irregularidades observadas que podem ser destacadas são:

- o manipulador do açaí realiza atividades, como recolher os caroços provenientes do despolpamento e jogá-los no lixo, com as mesmas luvas que utiliza para a lavagem dos frutos e o processo de obtenção da polpa;

- geralmente, o mesmo manipulador que realiza o despolpamento dos frutos, realiza a venda do produto, mantendo contado com o dinheiro;

- a touca é colocada muitas vezes com o manipulador já utilizando as luvas;

- panos de limpeza são utilizados continuamente para limpar o local de processamento;

- nos estabelecimentos abertos, como feiras livres e "batedeiras", podem ocorrer contaminações em função do contato direto de fumaças vindo dos carros, poeira, insetos, entre outros. 


\title{
4 Conclusão
}

A avaliação de polpas de açaí comercializadas em Belém, PA, mostrou que das amostras analisadas, todas apresentaram contaminação por coliformes, no valor de $\geq 1,1 \times 10^{2} \mathrm{NMP} / \mathrm{g}$ e fungos filamentosos e leveduras (variando de $9,0 \times 10^{2} \mathrm{UFC} / \mathrm{g}$ a $5,5 \times 10^{5} \mathrm{UFC} / \mathrm{g}$ ). Em duas amostras verificou-se a presença de Salmonella e em nove, a presença de Escherichia coli. Nenhuma das amostras atendeu aos requisitos da legislação sanitária brasileira para polpa de frutas. Desta forma, o problema da contaminação da polpa de açaí deve ser analisado desde a colheita dos frutos até a sua comercialização, ou seja, em toda a sua cadeia produtiva, para se determinar quais os pontos críticos e de controle.

\section{Agradecimentos}

Ao PRODETAB (Projeto de Apoio ao Desenvolvimento de Tecnologia Agropecuária para o Brasil) pelo auxílio financeiro.

\begin{abstract}
Açaí (Euterpe oleracea Mart.), the fruit from a palm tree native of Amazon, arouses among other vegetable sources for its anthocyanins rich pulp, which is largely consumed in the production region and that has its commercialization to other states in Brazil and also to foreign countries continuously increasing. The usual conditions in açaí processing, carried out by small processors distributed in different commercialization points, may be a potential risk for people healthy due to the lack of adequate sanitary infrastructure and practices. This work aimed the analysis of the sanitary quality of açaí pulp in ten commercialization points in Belém city, PA: four supermarkets, two free markets and four sell points, usually called "batedeiras". Analysis of Salmonella, fecal coliforms, Escherichia coli and molds and yeasts were performed. All the ten analyzed samples presented fecal coliforms in the range of $\geq 1.1 \times 10^{2} \mathrm{MPN} / \mathrm{g}$ and molds and yeasts varying from $9.0 \times 10^{2}$ to $5.5 \times 10^{5} \mathrm{CFU} / \mathrm{g}$. In two samples Salmonella was detected and nine samples presented Escherichia coli. According to the results, it was possible to verify that all samples did not attended the standard requirements recommended by ANIVSA, suggesting the necessity of implementation of Good Manufacturing Practices in this important regional production.
\end{abstract}

Key-words: Euterpe oleracea, sanitization, Salmonella, Escherichia coli, fungi, yeasts.

\section{Referências}

AVILA, C. R.; GALlO, C. R. Pesquisa de Salmonella spp. em Leite cru, leite pasteurizado Tipo C e queijo "minas frescal" comercializados no município de Piracicaba - SP. Scientia Agricola, v. 53, n. 1, p. 159-163, 1996.

BRASIL. Agência Nacional de Vigilância Sanitária. Resolução - RDC n 12, de 2 de janeiro de 2001. Diário Oficial da União, 2001.

BRASIL. Ministério da Agricultura e do Abastecimento. Instrução Normativa $\mathrm{n}^{\circ}$ 1, de 7 de janeiro de 2000 . Diário Oficial da União, 2000. 
CAVALCANTE, P. B. Frutas comestíveis da amazônia. 5 ed. Belém: CEJUP, 1991. 279 p.

FRANCO, B.D.G.M.; LANDGRAF, M. Microbiologia dos Alimentos. São Paulo: Editora Atheneu, 182 p., 1996.

NOGUEIRA, O. L.; CARVAlHO, C. J. R.; MUlleR, C. H.; GALVÃO, E. U. P.; SILVA, H. M. E.; RODRIGUES, J. E. L. F.; OLIVEIRA, M. S. P.; CARVALHO, J. E. U.; ROCHA NETO, O. G.; NASCIMENTO, W. M. O.; CAlZAVARA, B. B. G. A cultura do açaí. Brasília: EMBRAPA, 1995. 49p.

VANDERZANT, C.; SPLITTSTOESSER, D. F. Compendium of methods for the microbiological examination of foods. 3 ed. American Public Health Association. 1992.

VASCONCELOS, M. A. M.; ALVES, S. M. Colheita e pós colheita. In: Sistema de Produção, 4. Açaí Editado por NOGUEIRA, O. L; FIGUEIRÊDO, F. J. C.; MÜLLER, A. A. Embrapa Amazônia Oriental, p.86-96, 2005.

Submetido em 03 mai. 2010; Revisão submetida pelos autores em nov. 2011; Aceito para publicação em 09 dez.2011. 